\title{
US donor pushes Japan on organ transplantation
}

Japanese doctors, exasperated by their country's unwillingness to recognize "brain death" as death and to legally outline donor consent requirements, are considering using organs harvested from cadavers at five US military hospitals in Japan to perform heart and liver transplantations. The Japan Society for Transplantation announced that it is setting up a working group to draw up guidelines for the use and acceptance of organs donated by "brain dead" donors, including donors from military hospitals at US bases in Japan. American doctors at these hospitals, like their colleagues back home, recognize the criterion of brain death. Although heart and liver transplants are not technically illegal in Japan, they are not performed (Nature Medicine 2, 835; 1996).

The society's decision to launch guidelines on the issue follows the recent failure by the Japanese Diet (parliament) to pass an organ transplant bill. It was hoped the bill would finally make the legality of transplants explicit and would support a clear criterion of brain death. The Diet was, however, dissolved in preparation for
October's parliamentary election before a vote on the bill could be held, bringing an abrupt end to the bill's passage. It will now have to be reintroduced, and it could take several more years before Japanese legislators finally vote on the issue.

Japanese doctors say they can no longer wait and are looking for ways to force a "breakthrough." Some doctors are considering going ahead and harvesting hearts and livers from Japanese donors who have suffered from neurovascular diseases and are "clearly dead." Kikuo Nomoto, chairman of the Japan Society for Transplantation, is unwilling to rule out this possibility, but would prefer building Japanese consensus on the issue.

Efforts to push acceptance of brain death, and thus heart and liver transplants, received a strong boost in September, when two kidneys from an American were donated to Japanese recipients from a US military hospital at the US Naval base at Yokosuka, near Yokohama. The parents of the donor, a 5-year-old boy who died after a freak accident, asked that the organs be donated in Japan. US military doctors at the base approached the transplant society, saying that organs might be available for transplantation. Subsequently, the society accepted two kidneys, which have now been transplanted into two Japanese patients (a 9-year-old and a 19-year-old), chosen from Japan's national waiting list (consisting of approximately 2,000 patients).

This case brings more pressure to bear on the government to come to grips with the current situation. Although the society is currently unable to accept hearts and livers from US donors, it intends to do so after it has drawn up guidelines on the issue, according to Nomoto. Such donations will likely require some sort of agreement between the US military and the Japanese government, but the society hopes its guidelines (which will be announced next year) will lead to the reintroduction of heart transplants and Japan's first-ever complete liver transplant. The society also hopes that the guidelines will provide the public a better understanding of the life-saving potential of donating organs.

RICHARD NATHAN Tokyo, Japan

\section{Généthon shifts its focus}

After several years of marginal involvement in gene therapy, France now appears poised to compete in the race to improve gene delivery systems. A large research center dedicated to vector biology recently opened in the Paris suburb of Evry. The new center is under the direction of Olivier Danos of the Centre National du Recherche Scientifique and former scientific director of Somatix, a US biotech company.

Because of the spending freeze imposed by the French government, as well as the weak budget for research, this initiative is being entirely underwritten by the Association Française contre les Myopathies (AFM). The private association plans to invest the project with US\$18 million over the next five years, and will establish the new vector biology center in Généthon, another AFM creation, which until now has been dedicated to gene mapping.

"This budget is sufficient to develop a good research program which will focus on several vectors at the same time," says Danos. Planned studies include not only adenoviral and retroviral vectors, but also adeno-associated virus (AAV), as well as nonviral vectors such as cationic polymers. "The future [of gene therapy] lies certainly in combining these different vectors," says Danos, "but for the short term, we must learn more about their immunogenicity, their gene regulation and expression and how they interact with target cells."
Clearly, the amount AFM is investing in vector biology is not sufficient to support clinical trials as well. But "there is certainly no rush to immediately obtain huge resources for clinical trials," according to Alain Fischer of INSERM, who, together with Jean-Michel Heard from the Pasteur Institute, has recently opened a gene therapy research center at the Necker Hospital in Paris. Fischer notes that in his field - the transfer of genes into hematopoietic cells - basic scientific problems, such as suitable vectors, are far from solved.

Even if good vectors were known, no center is capable of producing them according to "good manufacturing practice" (GMP). In France, unlike the USA (which has a number of such centers), only the biotech companies Transgène and Gencell are capable of such production. Transgène, however, targets cancer, AIDS and cystic fibrosis, and Gencell focuses on cancer. Genopoïetic, a new company that recently started producing GMP vectors for two cancer clinical trials, may scale up its production in the future to meet the research community's needs.

Although basic research on vectors is the first priority of Danos and the AFM, they plan to implement a pilot project of vector production at Evry next year.

CATHERINE TASTEMAIN Paris, France 